\title{
The application of statistical methods in the study of unprofitable organizations' activities
}

\author{
Dmitry Dianov ${ }^{1, *}$, Alexander Suglobov ${ }^{2}$, and Angelina Dyatlova ${ }^{1}$ \\ ${ }^{1}$ Moscow University Ministry of Internal Affairs of the Russian Federation Named after V. J. Kikot, \\ 107007, Okruzhnoy proezd, 4, Moscow, Russia \\ ${ }^{2}$ Financial University under the Government of the Russian Federation, 125993, Leningradskiy \\ prospect, 49, Moscow, Russia
}

\begin{abstract}
Unprofitable organizations rarely fall under the monitoring of the economic development of territorial entities. Rather, they are the object of study of forensic economic examination, appointed, for example, to establish the facts of false bankruptcy. Is the unprofitability identical to the failure of investment projects, and is it possible to put an equal sign between these categories and phenomena? Unprofitability of organizations is not always associated with criminal aspects or incompetent management. Often, the reasons can be so independent of managers that one just has to watch how a firm or business rolls down. These are economic reasons, for example, the appearance of powerful competitors-producers or substitute goods; this is also administrative reasons, caused by an imbalance in the relationship between business and government, the needs of officials and the "cashier" of entrepreneurs. In addition, a huge number of organizations, especially in mining and agrarian industries are planned loss-making: it relates to all industrially developed economies in the world. Thus, from the perspective of investment research, the question of their effectiveness and profitability is legitimate. The ratio of planned and unplanned unprofitability is a delicate matter, relative to the budget system. The problematic nature of these issues is manifested, both in theoretical and practical-management aspects. The adoption of any decisions on these issues is impossible without proper and adequate quantification of such a phenomenon in the economy, as the unprofitability of organizations. A comprehensive quantitative assessment is in the competence and theoretical and methodological field of statistical science. It is the application of statistical tools for the study of unprofitable organizations that this research is devoted to, as presented in the article
\end{abstract}

\section{Introduction}

The topic of unprofitability of organizations does not raise doubts in its actuality, as unprofitable organizations are inevitable, both for market and planned economy.

Unprofitability of organizations, as an economic phenomenon, can be viewed as an indicator of the state, results and development of business, and at the same time it is an

* Corresponding author: skad71@ mail.ru 
incentive to improve this business and the economy. Every year during the last decade, almost all large and medium-sized organizations finish their fiscal year with a loss and do not pay a profit tax, which, in turn, is one of the main income-generating items in the budget. This can be regarded as an actual economic issue.

The unprofitability of an enterprise should be considered as a financial condition of an organization when its cash receipts are inadequate to the needs for both current and capital expenditure related to the implementation of economic activity: profit is equal to zero or close to that, and financial obligations, including unsecured ones, grow.

The object of this study is to define the activities of unprofitable organizations in the context of the municipal districts of the Vladimir region; the subject of the research will be a quantitative assessment of the activities of unprofitable organizations on the basis of the application of statistical methods and indicators characterizing the results and factors determining the state of the designated object.

The purpose of the study is defined as a complex statistical analysis of loss-making organizations. At the same time, the main task is to test statistical methods, which should form the basis of the methodology of this statistical analysis that is of complex nature. In the process of research, statistical information from the official Rosstat (The Federal State Statistics Service) website, and information presented in official statistical publications, as well as specialized scientific publications (monographs), periodic mass media materials, Internet resources were used.

\section{Systematization of statistical information}

\subsection{Statement of the problem of applying the method of analytic groupings}

In order to get an idea of the socio-economic development of the regions, it is necessary to establish the interrelations and interdependencies between the most significant socioeconomic indicators of these regions, as well as to determine the impact of some indicators of socio-economic development on others, and subsequently reveal the patterns of this change. In order to reveal the dependence of some socio-economic indicators on others, it is necessary to apply the method of analytical groupings and the correlation and regression method.

In statistics, the method of groupings is a continuation of the statistical summary: after all the information on all units of observation has been brought together and checked to meet the requirement of statistical homogeneity, it is necessary to break up the whole array of units - in this case, these are districts of the constituent entity of the Federation - into homogeneous groups or socio-economic types. In multidimensional grouping, they are called clusters. In our study, the grouping is carried out in order to obtain the most general idea of the structure of activities of unprofitable organizations, to identify and, if possible, to establish interrelations and interdependencies between the resulting and explanatory (grouping) indicators.

Applying the method of groupings, we will reveal the dependence of the financial result of unprofitable organizations on the number of unprofitable organizations. That is, we will check how the extensive factor affects the result.

The main objective of this stage of the study is to identify the existence of a relationship between the number of unprofitable organizations, the financial result of loss-making organizations, accounts receivable and accounts payable, as well as arrears in payments to the budget from the total amount of accounts payable, and debts to suppliers and contractors for goods, works and services from the total amount of accounts payable. 
Let us designate the scientific hypothesis as the assumption that the more loss-making organizations will be within the territories of the municipal districts of the Vladimir region, the higher is the financial result of unprofitable organizations. The logic is that loss-making organizations should not be viewed as failure investments: they can continue and de facto continue carrying out their activities, create value and contribute to the creation of a gross regional and domestic product.

We will carry out a statistical analysis of the relationship between individual socioeconomic indicators for the sixteen municipal districts of the Vladimir region on the basis of the actual data for 2016.

\subsection{Implementation of practical calculations for the formation of socio- economic types}

To assess the cause-effect relationships in relation to the set purpose and the generated array of input data, it is necessary to determine what indicators will be resulting, explanatory, and grouping. As a rule, the grouping indicator, that is, the one that will form the basis of the grouping is selected from among the explanatory indicators.

As a resulting indicator "Y", the financial result of loss-making organizations was adopted. As explanatory indicators, the following ones are selected:

X1 - Accounts receivable of organizations;

$\mathrm{X} 2$ - Accounts payable of organizations;

$\mathrm{X} 3$ - Arrears in payments to the budget from the total amount of accounts payable;

X4 - Indebtedness to suppliers and contractors for goods, works and services from the total amount of accounts payable;

X5 - The number of unprofitable organizations

Table 1 Economic indicators of the municipal districts of the Vladimir region in 2016, thousand rubles.

\begin{tabular}{|c|c|c|c|c|c|c|c|}
\hline No & 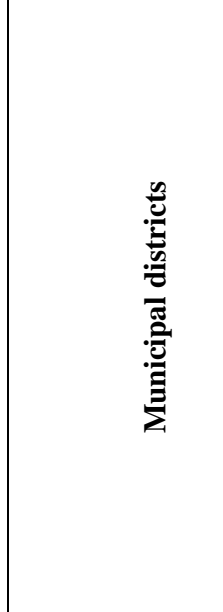 & 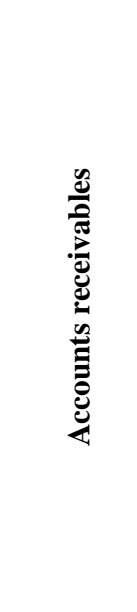 & 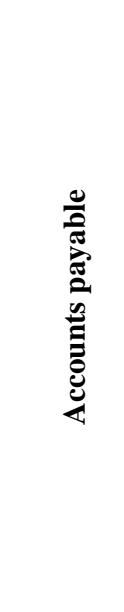 & 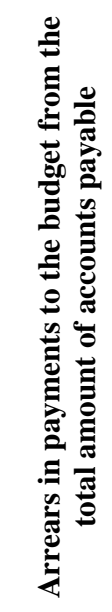 & 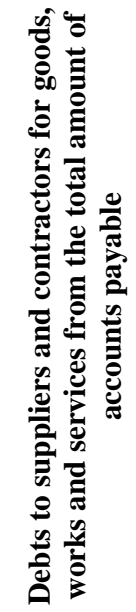 & 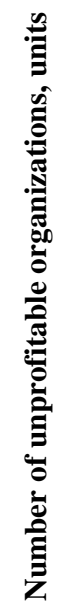 & 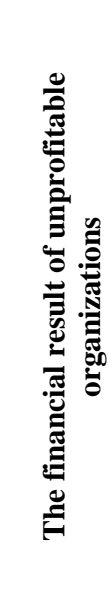 \\
\hline 1 & Aleksandrovskii & 3614273 & 6572872 & 289097 & 5317180 & 14 & 396849 \\
\hline 2 & Viaznikovskii & 747196 & 1411486 & 131619 & 931858 & 8 & 222048 \\
\hline 3 & Gorokhovetskii & 1255606 & 655332 & 25494 & 447174 & 3 & 33313 \\
\hline 4 & Gus-Khrustalnyi & 1454678 & 1852585 & 185922 & 1070856 & 4 & 464141 \\
\hline 5 & Kameshkovskii & 1541514 & 893671 & 34691 & 524116 & 2 & 15103 \\
\hline 6 & Kirzhachskii & 4498063 & 2938709 & 187322 & 2322170 & 4 & 180549 \\
\hline
\end{tabular}




\begin{tabular}{|c|l|c|c|c|c|c|c|}
\hline 7 & Kovrovskii & 397603 & 218009 & 36943 & 130124 & 3 & 39677 \\
\hline 8 & Kolchuginskii & 3948050 & 12359691 & 3322252 & 6251434 & 11 & 7244888 \\
\hline 9 & Melenkovskii & 543515 & 390324 & 57294 & 236943 & 1 & 8987 \\
\hline 10 & Muromskii & 120197 & 62678 & 765 & 25334 & 4 & 7879 \\
\hline 11 & Petushinskii & 15125896 & 19812327 & 1146513 & 17747102 & 13 & 607190 \\
\hline 12 & Selivanovskii & 176249 & 58409 & 17784 & 30422 & 2 & 1669 \\
\hline 13 & Sobinskii & 10337751 & 6805237 & 1157839 & 4509675 & 7 & 31164 \\
\hline 14 & Sudogodskii & 309004 & 226318 & 28356 & 153787 & 2 & 1604 \\
\hline 15 & Suzdalskii & 588116 & 655765 & 37734 & 459589 & 7 & 95701 \\
\hline 16 & Yuriev-Polskii & 1569772 & 1383626 & 55496 & 1025165 & 5 & 25342 \\
\hline
\end{tabular}

As a grouping indicator, we take X5. The effect of this indicator on the result can be considered the most hidden, and therefore, of interest for statistical analysis of relationships. Visually, there is a positive relationship between the quantity and financial result of the activities of unprofitable organizations.

Let us build the grouping according to X5. To do this, one needs to split the data array into groups. To do so, we find the number of groups.

$\mathrm{R}=\mathrm{Xmax}-\mathrm{Xmin}$, where:

$\mathrm{R}$ is the variation range; $\mathrm{Xmax}$ is the maximum value of $\mathrm{X} 1$; $\mathrm{Xmin}$ is the minimum value of the variable $\mathrm{X} 5$.

Variation range: $\mathrm{R}=14-1=13$ units.

The number of groups is determined by the Sturges rule: $\mathrm{N}=1+\operatorname{Lg}(\mathrm{n}) * 3,322$.

Hence, $\mathrm{N}=5$ groups.

The width of the interval is determined by the formula $h=\mathrm{R} / \mathrm{N}=3$ units.

Table 2 Distribution of districts of the Vladimir region by groups.

\begin{tabular}{|c|c|c|}
\hline Group number & Number of unprofitable organizations & District number \\
\hline 1 & Up to 4 & $3,4,5,6,7,9,10,12,14$ \\
\hline 2 & 4 to 7 & $13,15,16$ \\
\hline 3 & From 7 and more & $1,2,8,11$ \\
\hline
\end{tabular}

The distribution of municipal districts by the grouping indicator - the number of unprofitable organizations - is visualized on the Figure 1.

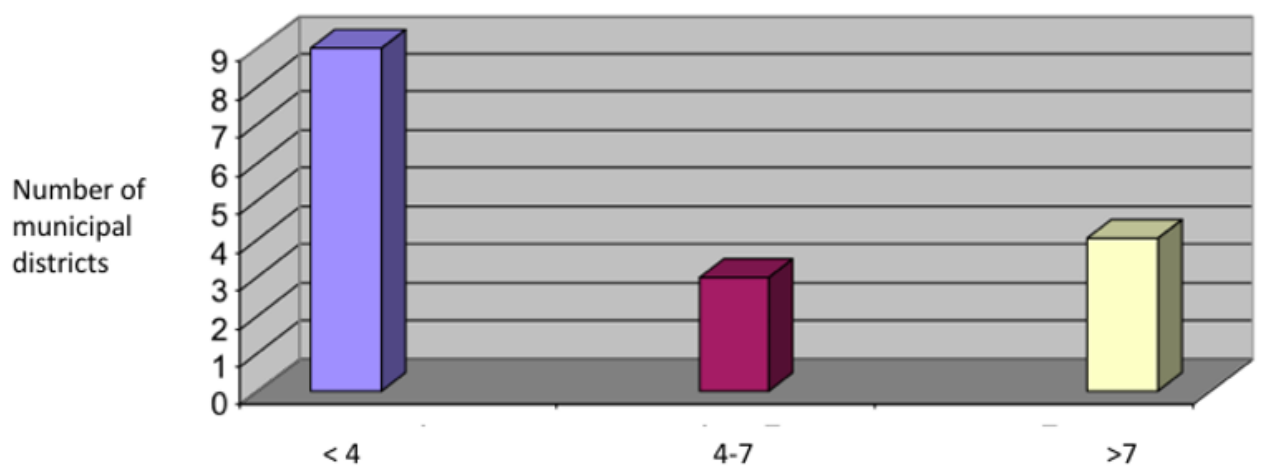

Fig. 1. Distribution of municipal districts of the Vladimir region by the number of unprofitable organizations in 2016. 
Submission of such scattering of points to the normal distribution law is highly doubtful, since the most characteristic districts are those, on the territory of which the number of unprofitable organizations is less than four. The distribution of financial results and liabilities by the formed groups, constructed by the indicator of the number of unprofitable organizations is of special interest for the analysis of the structure of the phenomenon being studied.

Based on the resulting distribution, we can calculate the average values of all indicators for each of the groups. To do this, let us construct a calculation table.

Table 3. Calculation of the average values of indicators by the groups of municipal districts of the Vladimir region in 2016, thousand rubles.

\begin{tabular}{|c|c|c|c|c|c|c|c|}
\hline $\mathbf{n}$ & 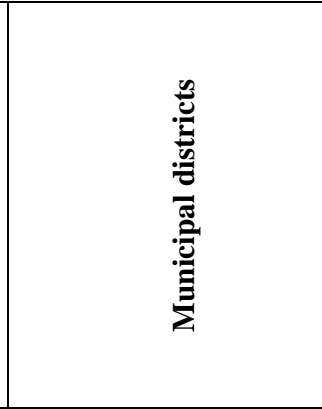 & 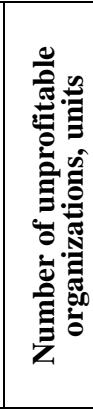 & 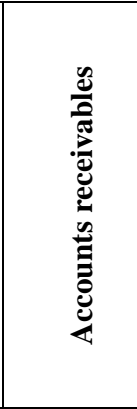 & 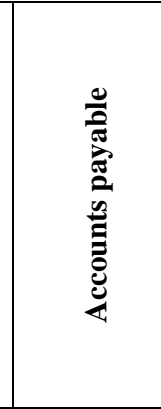 & 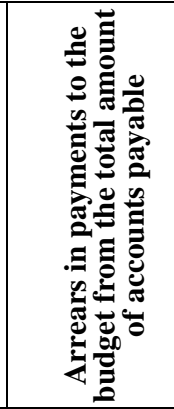 & 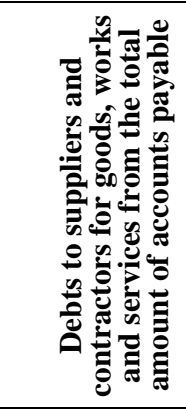 & 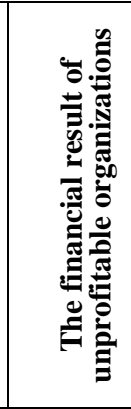 \\
\hline 9 & Melenkovskii & \multirow{9}{*}{$\begin{array}{l}\text { Up to } \\
4\end{array}$} & 543.515 & 390.324 & 57.294 & 236.943 & 8.987 \\
\hline 5 & Kameshkovskii & & 1541.514 & 893.671 & 34.691 & 524.116 & 15.103 \\
\hline 2 & Selivanovskii & & 176.249 & 58.409 & 17.784 & 30.422 & 1.669 \\
\hline 4 & Sudogodskii & & 309.004 & 226.318 & 28.356 & 153.787 & 1.604 \\
\hline 3 & Gorokhovetskii & & 1255.606 & 655.332 & 25.494 & 447.174 & 33.313 \\
\hline 7 & Kovrovskii & & 397.603 & 218.009 & 36.943 & 130.124 & 39.677 \\
\hline 4 & Gus-Khrustalnyi & & 1454.678 & 1852.585 & 185.922 & 1070.856 & 464.141 \\
\hline 6 & Kirzhachskii & & 4498.063 & 2938.709 & 187.322 & 2322.17 & 180.549 \\
\hline 0 & Muromskii & & 120.197 & 62.678 & 0.765 & 25.334 & 7.879 \\
\hline & Amount & & 10296.43 & 7296.035 & $\mathbf{5 7 4 . 5 7 1}$ & 4940.926 & 752.922 \\
\hline & Average for 1 group & & 1144.047 & 810.67056 & 63.841222 & 548.9917778 & 83.658 \\
\hline 6 & Yuriev-Posadskii & \multirow{3}{*}{$4-6$} & 1569.77 & 1383.626 & 55.496 & 1025.165 & 25.342 \\
\hline 3 & Sobinskii & & 10337.75 & 6805.237 & 1157.839 & 4509.675 & 31.164 \\
\hline 5 & Suzdalskii & & 588.116 & 655.765 & 37.734 & 459.589 & 95701 \\
\hline & Amount & & 12495.64 & 8844.628 & 1251.069 & 5994.429 & 152.207 \\
\hline & Average for 2 group & & 4165.213 & 2948.2093 & 417.023 & 1998.143 & 50.73567 \\
\hline 2 & Viaznikovskii & \multirow{4}{*}{$\begin{array}{l}7 \text { and } \\
\text { more }\end{array}$} & 747.196 & 1411.486 & 131.619 & 931.858 & 222.048 \\
\hline 8 & Kolchiginskii & & 3948.05 & 12359.691 & 3322.252 & 6251.434 & 7244.888 \\
\hline 11 & Petushinskii & & 15125.89 & 19812.327 & 1146.513 & 17747.102 & 607.19 \\
\hline 1 & Aleksandrovskii & & 3614.273 & 6572.872 & 289.097 & 5317.18 & 396.849 \\
\hline & Amount & & 23435.42 & 40156.376 & 4889.481 & 30247.574 & 8470.975 \\
\hline & Average for 3 group & & 5858.853 & 10039.094 & 1222.37025 & 7561.8935 & 2117.744 \\
\hline & Total by the region & & 46227.48 & 56297.039 & 6715.121 & 41182.929 & 9376.104 \\
\hline & Average by the region & & 2889.218 & 3518.564 & 419.69506 & 2573.933 & 586.007 \\
\hline
\end{tabular}


The final values of the indicators for all three groups are to be payed attention. If the first group, which includes the majority of municipal districts - 9 of 16 - concentrates the financial result of unprofitable organizations in the amount of 752.9 thousand rubles (or only $8.03 \%$ of the total financial result of the region as a whole), then the four regions composing the third group accumulate the amount by the resulting indicator in the value exceeding 8470 thousand rubles. The share of the third group exceeds $90 \%$ in terms of financial performance of loss-making organizations (the second group - 1.62\%). The situation is similar for the rest of the indicators, indicated as explanatory. This only indicates planned loss-making, or non-competitiveness of the analyzed organizations in most districts of the Vladimir region. At the same time, speaking about these organizations in this very majority, it should be noted that the scale of their activities, judging from the data in the Table 3, is insignificant. Each of the four districts of the third group Viaznikovskii, Kolchuginskii, Petushinskii and Aleksandrovskii - has more than 7 lossmaking organizations on its territory, and as noted above, the financial result of their activities has the largest share, which indicates the actual effectiveness of programs, measures and individual actions to support organizations, and, consequently, the employed population.

After the districts of the constituent entity of the Federation are distributed according to homogeneous groups and the average group values of indicators are calculated, it is possible to build an analytical grouping.

Based on the results of the grouping, we can state that the more is the number of unprofitable organizations, the more is the financial result of their activities, the receivables and payables. This only shows that organizations continue to conduct real economic activities, working not only through budgetary subsidies, but also on the accumulated potential, formed trade and financial contacts and schemes, as evidenced by the positive direction of the relationship between debt indicators and the financial result. There is also an increase from the group to the group of the indebtedness indicator for payments to the budget (out of the total amount of accounts payable), which cannot be unequivocally regarded as a negative phenomenon, as the growth of this type of debt, indicates the availability of a tax base - the value created by these organizations, that is a part of the regional product.

Table 4. Grouping of municipal districts of the Vladimir region by the number of unprofitable organizations in 2016.

\begin{tabular}{|c|c|c|c|c|c|c|c|}
\hline No & 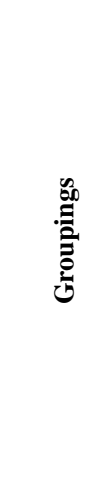 & 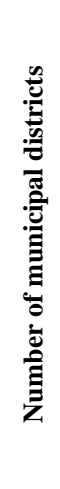 & 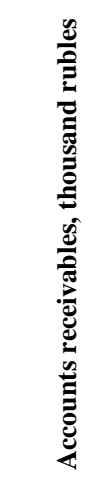 & 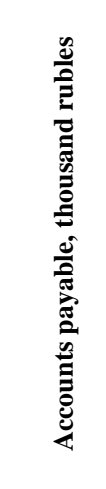 & 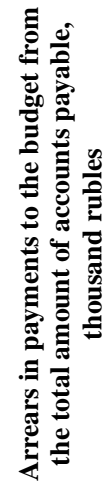 & 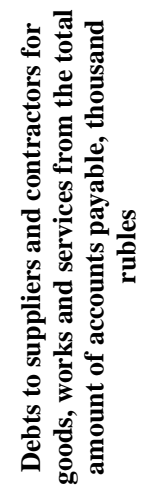 & 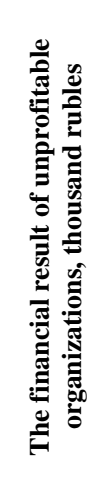 \\
\hline 1 & Up to 4 & 9 & 1144.04 & 810.67 & 63.84 & 548.99 & 83.66 \\
\hline
\end{tabular}




\begin{tabular}{|c|c|c|c|c|c|c|c|}
$\mathbf{2}$ & 4 to 7 & 3 & $\mathbf{4 1 6 5 . 2 1}$ & $\mathbf{2 9 4 8 . 2 1}$ & $\mathbf{4 1 7 . 0 2}$ & $\mathbf{1 9 9 8 . 1 4}$ & $\mathbf{5 0 . 7 4}$ \\
\hline $\mathbf{3}$ & 7 and more & 4 & $\mathbf{5 8 5 8 . 8 5}$ & $\mathbf{1 0 0 3 9 . 1 0}$ & $\mathbf{1 2 2 2 . 3 7}$ & $\mathbf{7 5 6 1 . 8 9}$ & $\mathbf{2 1 1 7 . 7 4}$ \\
\hline \multicolumn{3}{|c|}{ Average by the region } & $\mathbf{2 8 8 9 . 2 2}$ & $\mathbf{3 5 1 8 . 5 6 4}$ & $\mathbf{4 1 9 . 6 9}$ & $\mathbf{2 5 7 3 . 9 3}$ & $\mathbf{5 8 6 . 0 1}$ \\
\hline
\end{tabular}

\subsection{Primary assessment of the correlation ratio between indicators}

In order to quantify the correlation between the grouped (number) and resultant (financial result) indicators, it is required to calculate the empirical determination coefficient and the empirical correlation ratio:

$$
\begin{aligned}
& \eta^{2}=\frac{\delta^{2}}{\sigma^{2}} \text { empirical determination coefficient } \\
& \eta=\sqrt{\eta^{2}} \text { - empirical correlation ratio }
\end{aligned}
$$

To do this, it is necessary to measure the variation of the indicator of the financial result of the activities of unprofitable organizations - the total dispersion, and the inter-group dispersion, which is a part of the overall variance that shows how much of the dispersion the variation of the grouping indicator, that is the number of unprofitable organizations, takes for itself (or explain). The total variance $(\sigma 2)$ is equal to 9437811,553 thousand rubles.

Intergroup dispersion is calculated by the formula of the weighted mean square, because the groups are numerically unequal:

$\delta 2=115689313.9 / 16=7230582.12$ thousand rubles ${ }^{2}$.

To quantify the relationship between the grouping indicator and the resultant indicator, an empirical determination coefficient is calculated that shows how much of the variance of the resultant attribute is due to the influence of the independent variable that is the basis of the grouping.

Then the empirical determination coefficient will amount to: $\eta^{2}=7230582.12$ / $9437811.553 * 100 \%=76.61 \%$.

Then the empirical correlation ratio: $\eta=0.875$.

Variance of the financial result indicator by unprofitable organizations by more than $76.61 \%$ is explained by the grouping indicator - by their number. The correlation relation takes on a value in the interval $(0 ; 1)$. In this case, a value equal to 1 gives us a functional relationship, and a value equal to 0 is interpreted as the absence of any relationship. The Chaddock scale, which reflects the quantitative measure of the significance of the relationship inseparably from the qualitative characteristics of the relationship being studied, makes it possible to characterize the value of 0.875 as a high degree of the correlation relationship between the quantity and the financial result of the unprofitable organizations in the Vladimir region in 2016.

Analysis of the financial results of unprofitable organizations is immeasurably more important than that of the well-off, working steadily and profitably, since it is an indispensable and integral part of the anti-crisis program. The solution of these tasks is developed by the units of the management system in order to stabilize the work of the organization and to overcome loss-making.

The hypothesis stating that with the increase in the number of unprofitable organizations in the municipal district of the Vladimir region, the financial result of unprofitable organizations will also increase was confirmed by the statistical calculations. Thus, unprofitable organizations, despite the associative, or even intuitive, view of them, are not missing capital or failure investments. 
From this statement, it follows that the relationship between such indicators as the financial result of unprofitable organizations, the number of unprofitable organizations; accounts receivable; accounts payable; debts on payments to the budget from the total amount of accounts payable; debt to suppliers and contractors for goods, works and services out of the total amount of accounts payable is quite high, which gives us grounds for more accurate studying the interrelated impact of different indicators of the performance of unprofitable organizations and socio-economic development. It is necessary to introduce in the initial data direct resource indicators, best of all labor and investment ones.

\section{Modeling the interrelations of the performance indicators of unprofitable organizations on the basis of the correlation and regression method}

\subsection{Obtaining quantitative estimates and parameters of the influence of factors on the financial result of unprofitable organizations}

Dependence of the financial result of unprofitable organizations on the state of financial calculations, the level of investment in fixed assets and other economic indicators can be identified and quantified using the method of correlation and regression. It is the correlation-regression analysis in statistics that is the main method and means of generalizing and analyzing statistical information about socio-economic processes in the life of society.

The correlation and regression method must be applied in order to simulate the interrelation of the performance indicators of unprofitable organizations and indicators of socio-economic development. Applying the method of correlation-regression analysis, it is necessary to reveal interrelations and interdependencies between socio-economic indicators by the municipal districts of the Vladimir region. This method is the main one in statistics for studying the relationship of phenomena.

The task is the following: applying the method of correlation-regression analysis, it is necessary to identify and quantify the dependence of the resultant indicator "Y" - the financial result of loss-making organizations - on the factor (explanatory) indicators:

$\mathrm{X} 1$ - Accounts receivable;

$\mathrm{X} 2$ - Investments in fixed assets from the municipal budget;

$\mathrm{X} 3$ - Accounts payable;

$\mathrm{X} 4$ - Average number of employees of organizations;

X5 - Shipped goods of own production

Based on the official data of the Federal State Statistics Service (http://www.gks.ru), let us generate the following initial data. 
Table 5. The financial result of loss-making organizations and the factors determining it in the municipal districts of the Vladimir region in 2016, thousand rubles.

\begin{tabular}{|c|c|c|c|c|c|c|c|}
\hline No & Municipal districts & 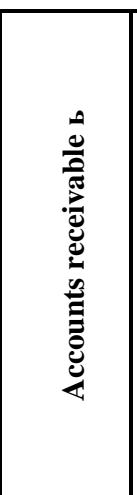 & 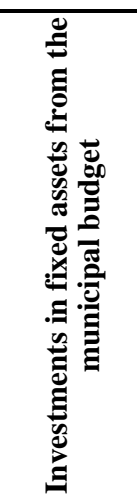 & 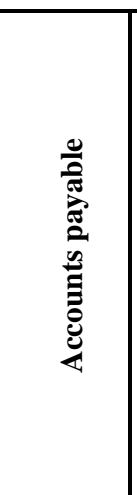 & 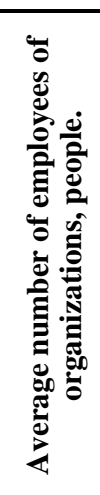 & 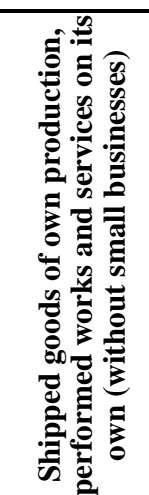 & 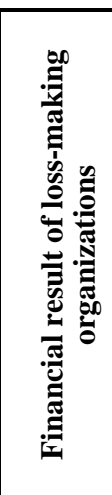 \\
\hline 1 & Aleksandrovkii & 3614273 & 1128856 & 6572872 & 14455 & 18940275 & 396849 \\
\hline 2 & Viaznikovskii & 747196 & 381685 & 1411486 & 12388 & 8395416 & 222048 \\
\hline 3 & Gorokhovskii & 1255606 & 846073 & 655332 & 3388 & 5083327 & 33313 \\
\hline 4 & Gus-Khrustalnyi & 1454678 & 181773 & 1852585 & 5025 & 6162682 & 464141 \\
\hline 5 & Kameshkovskii & 1541514 & 258164 & 893671 & 4627 & 7402870 & 15103 \\
\hline 6 & Kirzhachskii & 4498063 & 1807114 & 2938709 & 7476 & 15231647 & 180549 \\
\hline 7 & Kovrovskii & 397603 & 169128 & 218009 & 4368 & 2120392 & 39677 \\
\hline 8 & Kolchuginskii & 3948050 & 429433 & 12359691 & 9617 & 20068980 & 7244888 \\
\hline 9 & Melenkovskii & 543515 & 356681 & 390324 & 5029 & 2882763 & 8987 \\
\hline 10 & Muromskii & 120197 & 85617 & 62678 & 772 & 357121 & 7879 \\
\hline 11 & Petushinskii & 15125896 & 8677003 & 19812327 & 11202 & 43577124 & 607190 \\
\hline 12 & Selivanovskii & 176249 & 132375 & 58409 & 2563 & 1734900 & 1669 \\
\hline 13 & Sobinskii & 10337751 & 3129594 & 6805237 & 10540 & 54783457 & 31164 \\
\hline 14 & Sudogodskii & 309004 & 382388 & 226318 & 5802 & 3700766 & 1604 \\
\hline 15 & Suzdalskii & 588116 & 630091 & 655765 & 6556 & 3838602 & 95701 \\
\hline 16 & Yuriev-Posadskii & 1569772 & 979064 & 1383626 & 6455 & 8096870 & 25342 \\
\hline
\end{tabular}

The application package analysis of Exel allowed obtaining the following matrix of the paired correlation coefficients.

Table 6. Matrix of the paired correlation coefficients.

\begin{tabular}{|c|c|c|c|c|c|c|}
\hline & Column 1 & Column 2 & Column 3 & Column 4 & Column 5 & Column 6 \\
\hline Column 1 & 1 & & & & & \\
\hline Column 2 & 0.936881 & 1 & & & & \\
\hline Column 3 & 0.876827 & 0.827751 & 1 & & & \\
\hline
\end{tabular}




\begin{tabular}{|c|c|c|c|c|c|c|}
\hline Column 4 & 0.558347 & 0.449014 & 0.614564 & 1 & & \\
\hline Column 5 & 0.933342 & 0.768621 & 0.771034 & 0.639019 & 1 & \\
\hline Column 6 (Y) & $\mathbf{0 . 1 2 7 9 0 2}$ & $\mathbf{- 0 . 0 3 3 5 7}$ & $\mathbf{0 . 4 9 6 7 7 4}$ & $\mathbf{0 . 2 5 1 8 7 5}$ & $\mathbf{0 . 1 7 0 1 7}$ & $\mathbf{1}$ \\
\hline
\end{tabular}

Based on the results of the conducted correlation analysis, it can be concluded that there is a strong positive relationship between the financial result of unprofitable organizations and accounts receivable, and the average number of employees of organizations. On this matrix, we also establish a moderate positive relationship between the financial result of unprofitable organizations and accounts payable, as well as the presence of a weak positive relationship between the financial result of unprofitable organizations and the number of shipped goods of own production. At the same time, the only negative value observed in the matrix is in relationship between the financial result and investments in fixed assets from the municipal budget, which can be considered as a definite signal in favor of the fact that investment flows carried out at the expense of municipal budgets need inventory. So informative is the sixth line, indicating a paired correlation of the financial result of unprofitable organizations and investments in fixed assets at the expense of municipal budgets, and also pairwise with other explanatory indicators. Correlation coefficients placed in the central part of the matrix characterize a pairwise relationship between the explanatory indices themselves. One of them indicates a high degree of relationship between the level of investment in fixed assets and the accounts payable of organizations, which can partly adversely affect the regression model to be built (the phenomenon of multicollinearity).

In order to determine the analytical expression of the relationship between the resulting and the explaining indicators, it is necessary to conduct a regression analysis - to construct an adequate model of dependence: to choose the most qualitative model from several possible options, that in the best way describes the process of forming the financial result of unprofitable organizations under the influence of factors included in this model.

Let us construct a regression model that describes the process of formation of the financial result of unprofitable organizations: the regression equation of the resultant indicator " $Y$ " as a function of five explanatory indicators: X1, X2, X3, X4, X5:

$$
\hat{\mathrm{Y}}(\mathrm{X} 1, \mathrm{X} 2, \mathrm{X} 3, \mathrm{X} 4, \mathrm{X} 5)=\mathrm{b} 0+\mathrm{b} 1 * \mathrm{x} 1+\mathrm{b} 2 * \mathrm{x} 2+\mathrm{b} 3 * \mathrm{x} 3+\mathrm{b} 4{ }^{*} \mathrm{x} 4+\mathrm{b} 5{ }^{*} \mathrm{x} 5
$$

Table 7. Regression statistics with all explanatory indicators taken into account.

\begin{tabular}{|c|c|c|c|c|}
\hline \multicolumn{2}{|c|}{ Regression statistics } & & coefficients & t-statistics \\
\hline Multiple R & 0.953401184 & Y-intersection & 759638.2031 & 1.985094902 \\
\hline R-square & $\mathbf{0 . 9 0 8 9 7 3 8 1 8}$ & The Variable X 1 & -0.262324276 & -1.877371657 \\
\hline Normalized R-square & 0.863460728 & The Variable X 2 & -1.007975906 & -2.006482517 \\
\hline Standard Error & 659840.7671 & The Variable X 3 & 0.623573738 & 6.993444848 \\
\hline Observations & 16 & The Variable X 4 & -131.6393021 & -1.783680523 \\
\hline & & The Variable X 5 & 0.041947615 & 2.531888116 \\
\hline
\end{tabular}

Based on the regression statistics obtained, it can be stated that the coefficient of determination (R-square) is 0.9089 , that is, the indicators included in the model explain the variation of the financial result of unprofitable organizations in the space of units municipal districts of the Vladimir region in 2016 explain on $90.9 \%$. 
Based on the results of the regression analysis (construction of all possible equations), it can be concluded (the mathematical aspect of choice) that the most appropriate is the first model, which includes all the explanatory indicators. This model is the most adequate, since the coefficient of determination of this model has the greatest value.

$$
\begin{gathered}
\hat{Y}(X 1, X 2, X 3, X 4, X 5)=759638.2031-0.262324276 * x 1-1.007975906 * x 2+ \\
+0.623573738 * x 3-131.6393021 * x 4+0.041947615 * x 5
\end{gathered}
$$

Let us calculate the elasticity coefficients based on this model. To do this, we will use both the regression parameters and the average values of the resultant and explanatory indicators:

$$
\begin{aligned}
& \mathrm{E} 1=\mathrm{b} 1 * \frac{\overline{\mathrm{x}}}{\overline{\mathrm{y}}}=-0.262324276 * 2889217.688 / 586006.5=-1,3 \% \\
& \mathrm{E} 2=\mathrm{b} 2 * \frac{\frac{\mathrm{x} 2}{\overline{\mathrm{y}}}}{\overline{\mathrm{x} 3}}=-1.007975906 * 1223439.938 / 586006.5=-2,104 \% \\
& \mathrm{E} 3=\mathrm{b} 3 * \frac{\frac{\mathrm{y}}{\overline{\mathrm{y}} 4}}{\mathrm{E} 4=\mathrm{b} 4 * \frac{\mathrm{y}}{\overline{\mathrm{y}}}=-131.6393021 * 6891.4375 / 586006.5=-1.55 \%} \\
& \mathrm{E} 5=\mathrm{b} 5 * \frac{\mathrm{x} 5}{\overline{\mathrm{y}}}=0.041947615 * 12648574.81 / 586006.5=0.905 \%
\end{aligned}
$$

All the necessary calculations have been made, which make it possible to proceed to the stage of interpreting the results of the statistical study.

\subsection{Interpretation of economic and mathematical results of the statistical study}

The constructed regression model for indicators characterizing the economy of the municipal districts of the Vladimir region in 2016 allows us establishing the following patterns.

With an increase in accounts receivable by 1 thousand rubles, a decrease in the financial result of unprofitable organizations by 0.26 thousand rubles is observed, probably for the reason that accounts receivable represent a debt to the organization, primarily for shipped products. In this case, it can be assumed that the stated situation is a symptom, albeit not a crisis, but a certain build-up of debts between organizations, connected primarily with the sale of products. Since debts to organizations increase (lack of payment for shipped products), they are deprived of the opportunity to fulfill their own financial obligations. Consequently, there are all kinds of penalties, fines and fees leading inevitably to the fact that the financial result is a loss due to debt repayment. In turn, problems with sales are everywhere now in the regions of central Russia due to a decline, first of all, the payment demands of the population on the consumer and other markets. That is, with an increase in accounts receivable by $1 \%$, the financial result of unprofitable organizations decreases by $1.3 \%$.

The growth of investments in fixed assets at the expense of the municipal budget by 1 thousand rubles is accompanied by a decrease in the financial result of unprofitable organizations by 1.007 thousand rubles. This clearly indicates that for municipal budgets unprofitable organizations are a "normative" burden, an anchor that the state simply has to drag out. These investments are not effective, and therefore they are accompanied by a decrease in the overall financial result of unprofitable organizations. With an increase in 
accounts receivable by $1 \%$, there is a decrease in the financial result of unprofitable organizations by $2.1 \%$.

The increase in accounts payable by 1 thousand rubles puts a positive sign for the financial result of unprofitable organizations by 0.62 thousand rubles, as it provides an opportunity to find additional sources of financing current costs, including those related to the marketing of products, and thereby partially stabilize economic activity. With an increase in accounts receivable by $1 \%$, the financial result of unprofitable organizations increases by $3.74 \%$.

With an increase in the average number of employees of organizations by one person, the financial result of unprofitable organizations is reduced by 131.6 thousand rubles, since an increase in the number of employees does not guarantee an improvement in the work process. In this situation, it can be assumed that the labor force is not appropriately divided, and hence the financial result decreases. At the same time, remuneration of labor is an element of cost price that reduces the financial result directly. In the cost-effective management, wage is considered a material incentive, but it is not the case. With an increase in accounts receivable by $1 \%$, the financial result of unprofitable organizations decreases by $1.55 \%$.

The indicator of the volume of shipped goods of own production, increasing by 1 thousand rubles, leads to an increase in the financial result of unprofitable organizations by 0.04 thousand rubles. This is a natural truth. That is, with an increase in the shipment of products by $1 \%$, the financial result of unprofitable organizations grows by $0.905 \%$.

It is expedient to continue the static analysis by analyzing the dynamics of the phenomenon under study. For this purpose, statistics have developed methods of analytical equalization and forecasting, index method, methods of relative values, etc.

\section{Conclusions}

The study of unprofitable organizations of the municipal districts of the Vladimir region presented in the scientific article is aimed at examining the analytical capabilities of statistical tools, represented by such methods as analytical groupings, correlation and regression, for a comprehensive assessment of factors determining the patterns of the financial result of these organizations. Undoubtedly, this research is an integral part of the overall monitoring of the economic development of territorial entities, which cannot be isolated from the statistical analysis of investment processes, development of market infrastructure, living standards, foreign economic relations, labor resources, migration, unemployment, social conditions and other important aspects social evolution.

In general, the testing of these methods that led to practical results based on fresh factual data can be considered rather successful. It should be noted that the application of the methods considered in the conduct of a comprehensive statistical analysis of lossmaking organizations is not exhaustive. Static and dynamic analysis can be performed on the basis of a variety of statistical methods, the application of which should be considered as a promising research direction.

\section{References}

1. E. Yu. Alekseicheva, M. D. Magomedov, Economics of organization (enterprise) (Dashkov \& K, Moscow, 2016)

2. R. S. Aisenov, R. A. Nabiyev, V. M. Semenov, Finance of enterprises (Finance and Statistics, Moscow, 2011) 
3. L. G. Batrakova, Social-economic statistics (Logos, Moscow, 2013)

4. S. V. Bolshakov, Finance of enterprises (Book world, Moscow, 2012)

5. V. V. Bocharov, Corporate finance (Piter, St. Petersburg, 2014)

6. T. I. Vasilevskaya, T. I. Vukilova, I. N. Zhuk, M. A. Zaitseva, Finance of enterprises (Higher School, Moscow, 2013)

7. A. N. Gavrilova, A. A. Popov, Finance of organizations (enterprises) (Knorus, Moscow, 2015)

8. G. B. Polyak, State and municipal finance (Unity, Moscow, 2016)

9. I. I. Dobroserdova, R. G. Popova, I. N. Samonova, Finance of enterprises (Piter, At. Petersburg, 2015)

10. S. A. Zaskoka, Crib: finance of enterprises, exam answers (Buklain, Moscow, 2013)

11. I. N. Ilina, K. S. Leonard, D. L. Lopatnikov, Regional economics and territorial development (Urait, Lubertsy, 2016)

12. D. V. Kislov, All about losses (Nalog Info, Moscow, 2011)

13. T. N. Kondratyeva, Finance of enterprises in schemes and tables (Higher School, Moscow, 2015)

14. V. V. Korshunov, Economics of organization (Urait, Lubertsy, 2016)

15. M. Lapusta, T. Mazurina,Finance of enterpsises (Alfa-Press, Moscow, 2014)

16. K. Lengdon, A. Bonhem, Finance (Eksmo, Moscow, 2012)

17. Yu. D. Maksimov, Mathematical statistics (Prospect, Moscow, 2016)

18. R. A. Shmoilova, Theory of statistics (Finance \& Statistics, Moscow, 2014)

19. Rosstat, Official website (Rosstat, 2017)

20. EbcyclopediaOfEconomics, Unprofitability of enterprises (Economy, Moscow, 2017)

21. Lybs.Ru, Enterprise reorganization management (Lybs, Moscow, 2017)

22. Studopedia, Finance of enterprises (Moscow, 2018)

23. PortalReferatov, Economic aspects of unprofitability of the enterprise (Minsk Institute of Management, Minsk, 2009)

24. R. Aktimerova, N. Yagarova, Work with unprofitable organizations (International economic forum, 2009) 